\title{
Comparison of Example-based Learning and Problem-based Learning in Engineering Domain
}

\author{
Lai Chee Sern", Kahirol Mohd Salleh, Nor lisa Sulaiman, Mimi Mohaffyza Mohamad , Jailani Md Yunos \\ Universiti Tun Hussein Onn Malaysia, Johor, Malaysia
}

Copyright (C) 2015 Horizon Research Publishing All rights reserved.

\begin{abstract}
The research was conducted to compare the impacts of problem-based learning (PBL) and example-based learning (EBL) on the learning performance in an engineering domain. The research was implemented by means of experimental design. Specifically, a two-group experiment with a pre- and post-test design was used in this research. A total of 37 students were randomly assigned to PBL and EBL groups. A pre- and post test were developed to measure learning performance. In addition, cognitive loads imposed by those learning strategies were gauged using NASA-TLX questionnaire. The results reveal that EBL is a more effective way to enhance learning performance and induces lower cognitive load during the process of learning and answering the test in comparison to PBL.
\end{abstract}

Keywords Example-based Learning, Problem-based Learning, Learning Performance, Cognitive Load

\section{Introduction}

Over the past few decades, substantial research has been conducted to evaluate the effectiveness of problem-based learning. Some previous research put the stress on examining the effectiveness of problem-based learning itself, without comparing it with other learning strategies (see [1], [2]); while other studies employed comparative methods to investigate the impacts of problem-based learning on learning outcomes in comparison to other pedagogical strategies. For example, [3] conducted a study to evaluate the performances of problem-based learning and lecture-based learning in psychiatry. They reported that students performed significantly better on examination when problem-based learning was employed, in comparison to lecture-based learning. Similarly, [4] have also conducted a study recently to compare the effects of problem-based learning and lecture-based learning on students' academic performance in public health course. The research findings showed that students exposed to problem-based learning demonstrated higher test scores and better recalling of learnt materials than those exposed to lecture-based learning strategy.

Although the effectiveness of PBL is apparently positive, this method is fruitful only if applied to the right persons (e.g., expert learners) and at the right time (e.g., after learners have gained sufficient content knowledge). It has been argued that PBL is not suitable for novice learners (see [5]). The reason that PBL is less efficient and less effective for novice learners is that PBL is a minimally guided learning strategy which assumes knowledge can best be learnt through experience based on the procedures of the discipline. Unguided or minimally guided instructions are usually less beneficial for novice learners because it provides inadequate guidance to the learners during the process of learning. The learners, therefore, might acquire misconception, incomplete, and disorganised domain knowledge [6].

Some researchers (e.g., [7], [8]) suggest that learners, especially the novice, should be fully guided throughout the initial learning phase. Instructionally, guidance can be done by providing worked examples to the learners. This supportive instructional strategy is commonly known as example-based learning (EBL). Worked examples are given to the learners in order to allow them to narrow down the knowledge gaps, and thereby constructing a complete problem solving model or representation.

Numerous empirical findings have demonstrated that both PBL (e.g., [3]) and EBL (e.g., [9]) have an positive impact on learning outcomes when they are applied to respective group of learners. However, empirical studies to compare the impact of PBL and EBL on learning performance are fairly scarce especially in the domain of engineering. In order to close this research gap, the present research was performed.

Additionally, from a cognitive load perspective, it is argued that learning by solving problems might induce higher cognitive load as compared to learning with worked examples [10]. More cognitive efforts are needed to solve a problem as compared to solely study a worked example. This is because cognitive effort is needed to process the problem state, goal state, and the operands to solve the problem. On the contrary, the learners who use EBL strategy do not have to invest a large amount of cognitive effort to look for solutions for the problems because the solutions procedures are shown in the worked examples. A question is raised: What is the level of cognitve effort invested by a learner when EBL and PBL are practised by learners? This question can be answered by conducting the current research. 


\section{Worked-Out Problem:}

When driving to work, Mrs. Fast has to pass the same traffic light twice - once in the moming and once in the evening. It is green in $70 \%$ of these cases. What is the probability that she can pass through a green light one time and has to stop one time?

Solution:

Quested: $\mathrm{p}$ (one time green and one time red)

$\mathrm{p}$ (green) $=7 / 10 ; \mathrm{p}($ red $)=3 / 10$.

There are 2 possibilities (green first andred second, or vice versa).

$\mathrm{p}($ one time green and one time red $)=7 / 10 \times 3 / 10 \times 2=21 / 50=.42$

Answer: The probability that Mrs. Fast can pass through a green light one time and has to stop one time is $\mathrm{p}=21 / 50=.42$.

Figure 1. Worked-Out Problem from [14].

\section{What is Example-based Learning and Problem-based Learning?}

(a) EBL

Learning from worked-out problems is able to provide students an initial idea of how to apply a theory, concept, or formula in a certain situation. In other words, worked-out problems are designed to support the initial acquisition of cognitive skills [11]. Most of the research articles in the existing literature provide a short but explicit definition of worked-out problem or worked example. Basically, a worked-out problem consists of a problem statement, solution procedures, and a final solution [12],[13]. The problem statement describes both the problem state and the goal state that needs to be achieved, whereas the solution procedures consist of a series of steps that lead to the final solution. In some cases, a worked-out problem can be presented in a graphical form, such as a chart and diagram. Figure 1 illustrates a typical worked-out problem in the domain of mathematics:

The worked-out problem (see Figure 1) shows the problem statement along with the step-by-step solution procedures. In a way, such example appears to be a professional problem-solving model for the students to learn and follow. In turn, this might help students construct a problem solving cognitive representation.

The employment of worked-out problem as a primary instructional tool in a learning process is regarded as EBL [14]. In general, the EBL is usually conducted in three basic steps. Firstly, the students are introduced to fundamental domain-specific knowledge. This is an important step because the students have to acquire some basic knowledge in order to understand the unfamiliar problem or terminology. Provision of domain-specific knowledge to students is even more important when they are involved in additional activities during the learning process. For example, if students are required to generate an explanation for a graphic diagram, they need to have had a certain level of prior domain knowledge in order to make that explanation meaningful.

Secondly, the students are presented with a series of worked-out problems, which contain both the problem statement and solutions. This important step is what makes the EBL unique, as presenting students with a solved problem is able to give them an idea of how a domain problem can effectively be solved. Additionally, the students will hopefully be able to acquire problem solving schema based on the problem solving examples. There are no rules to stipulate the format of worked-out problem presentation and some instructors practice more conventional way - showing the worked-out problem via the white-board or books while some use computer technology and multimedia elements in order to make the problem more presentable, authentic, and reaccessable [15]. It depends on the preferences of the individual instructor, as well as the availability of technology facilities. Another point worth stressing is that the worked-out problem instruction can be successfully combined with other learning activities, such as self-explanation prompts, tutor scaffolding, or giving feedback during the learning process.

\section{(b) PBL}

In reviewing the origins of PBL, its pioneers, [16], refer to PBL as:

"the learning that results from the process of working toward the understanding or resolution of a problem. The problem is encountered first in the learning process and serves as a focus or stimulus for the application of problem-solving or reasoning skills, as well as for the search for or study of information or knowledge needed to understand the mechanisms responsible for the problem and how it might resolved."

For [16], the idea behind PBL is that the problem drives the learning. That is, students are exposed to a problem before they develop the relevant domain knowledge on their own. The students are expected to gain knowledge through the process of solving the given problem, which functions as a stimulus to encourage students' thinking and engagement through the entire process of learning. It is important to note that teacher is not the primary source of information and that 
teacher-centred lecturing approach is not used in PBL; in fact, students are free to seek relevant information from various sources.

Specifically, PBL begins by requiring students to work on a real life problem, which is usually complex, ill-structured, and involves interdisciplinary contents. At this stage, students commonly have limited prior domain knowledge, because the domain knowledge has not yet been imparted to them. During the problem solving process, students attempt to identify the nature of the problem, which is preferably done in a group setting guided by a facilitator. After recognising the goal of the problem, the students have to develop and formulate some feasible strategies to solve the problem and determine what information they need to collect and which methodology they should apply. In the process of finding solutions, the students continue collecting and processing information that might be related to the problem. Eventually, all students are required to discuss and evaluate their final solutions with the assistance of a facilitator. Through this process, the students may develop profound and relevant knowledge of the subject area [17],[18]. In short, the operational concept of PBL can be summarised into five processes: first, identification of a problem; second, formulation of a strategy; third, collection of information; forth, problem solving; and lastly, evaluation of solutions.

PBL is seen by some as an effective didactical method to foster knowledge and problem solving skill acquisition, particularly in medical education [3],[2]. However, mixed past results make it difficult to come to a conclusive judgment about PBL.

\section{Cognitive Load Theory}

The positive effects of worked-out problem can be explained by cognitive load theory [19]. The genesis of cognitive load theory emerges from the assumption that working memory is limited to hold seven (plus or minus two) pieces of information simultaneously. However, it is typically difficult to hold this number of pieces information in working memory at any given time, because the memory is also used for cognitive processes - such as analysing, organising, and integrating information - which involve interactions between items of information. These cognitive processes consume a certain amount of working memory resource and thereby diminishing the quantity of information that can be concurrently held in the working memory [19]. As a consequence of this limitation, an individual will likely not be able to hold their personal maximum number of pieces of information at the same time. When working with a complex cognitive task, individuals usually have to deal with many interacting elements that have to be processed simultaneously in order to learn to perform that task or to successfully solve a problem. Thus, dealing with a task that contains a high number of interacting elements may induce a high demand on the working memory capacity. This demand on working memory capacity is regarded cognitive load [20].
In fact, any task that requires the processing of information in working memory with limited capacity will bring about a certain amount of cognitive load. However, it is not clear what aspects of a task might contribute to cognitive load. To provide insight into cognitive load, [21] have put forward a more precise concept of cognitive load, that is:

"Cognitive load, a multidimensional construct, represents the load that performing a particular task imposes on the cognitive system. The construct can be conceived to consist of causal factors and assessment factors affecting cognitive load and those affected by cognitive load."

This definition indicates that the load received by the cognitive system from any task execution is regarded as cognitive load. Various different parameters of a task may cause cognitive load, typically based on causal and assessment dimensions. From the aspect of the causal dimension, the task characteristics, personal characteristics, and the interaction between task and person are the contributors to cognitive load. The task characteristics concern the structure of the task, the difficulty of the task, the use of multimedia, and the length of time given to accomplish the task; whereas the personal characteristics are associated with the level of prior knowledge and the individual's ability to perform cognitive tasks. These personal characteristics are relatively stable and unlikely to experience abrupt changes when dealing with a task. Additionally, there are also unstable factors that might affect cognitive load. These factors, such as performance and motivation, are dependent on the task characteristics as well as personal characteristics [21].

\section{Objectives}

The present study examined the impact of using both EBL and PBL on students' learning outcomes in terms of learning performance in the domain of engineering, namely, Solid Mechanics. Apart from that, this study also looked at the relationship between cognitive effort and the learning performance. Specifically, the present research project aims at achieving the following objectives:

i. to find out the impact of EBL and PBL on learning performance in Solid Mechanics.

ii. to find out the level of cognitive load imposed by EBL and PBL.

\section{Methodology}

Research methodology is one of the most important components that guide researchers to collect data correctly in order to achieve the research objectives. In this section, the discussion of methodology will put the focus on research design, sampling, instruments, and treatment procedures. 


\section{Research Design}

The present research incorporated both a pre- and $\mathrm{i}$ post-measurement as well as two experimental groups. Basically, the present research design can be illustrated in the following diagram:

$$
\begin{aligned}
& \mathrm{O}_{1}-\mathrm{X}_{1}-\mathrm{O}_{2} \quad \text { (EBL group ) } \\
& \mathrm{O}_{3}-\mathrm{X}_{2}--\mathrm{O}_{4} \quad \begin{array}{c}
\text { (PBL group) } \\
\mathrm{X}=\text { treatment }
\end{array} \quad \mathrm{O}=\text { =measurement; }
\end{aligned}
$$

\section{Sampling}

The research subjects were selected from the second year students who registered for Solid Mechanics course at the Faculty of Technical and Vocational Education. The it participating students were randomly assigned to EBL group $(n=19)$ and PBL group $(n=18)$. The students were considered as novice as they hadn't taken any lectures or courses related to the to-be-learnt topic.

\section{Instruments}

\section{i. Pretest}

The assessment of prior knowledge was done to gauge the level of domain knowledge before the treatment. Multiple-choice items were used in the pretest in order to reduce the writing time, and more importantly, to reduce student's stress, considering this test were administered prior to the learning phase. The results of the pretest were used to check the comparability of the PBL and EBL groups.

\section{ii. Post-Test}

The post-test were conducted after the treatment and were used to measure the learning performance of the participants. The post test was composed of four problem solving tasks associated with Solid Mechanics (analysis of stress and strain in thin walled cylinders).

\section{iii. Cognitive Load/Mental Effort}

The rating scale method was used to collect the empirical data on cognitive load (mental effort) in this research. Specifically, the NASA Task Load Index (NASA-TLX), developed by [22], was used to assess the participant's intensity of cognitive load or mental effort throughout the experiments. The reliability analysis showed high Cronbach's Alpha, $\alpha=0.92$.

\section{Treatment Procedures}

EBL

Firstly, the prior knowledge of the participants were assessed using pretest. Secondly, they were taught about the fundamental domain knowledge on the analysis of stress and strain in thin walled cylinders (a subtopic of Solid Mechanics). Then, the participants were shown with several worked examples of problem solving related to the domain knowledge. After that, a post test was given to the participants to measure the learning performance. Lastly, NASA-TLX were distributed to all participants to measure mental effort.

\section{PBL}

Similarly, pretest was ultilised to measure the prior knowledge of the participants. Then, at the beginning of learning phase the participants were asked to solve several problems without exposing them to the domain knowledge. During the problem solving process, the participants were allowed to look up the reference materials and conduct discussion. And then, the participants were required to present their solutions in class. Feedbacks were provided if their solutions were incorrect. After that, the learning performance was measured by means of post test. At the final stage, the participants were required to complete the NASA-TLX.

\section{Results and Discussion}

The analysis of data was broken down into three parts, namely, analysis of pretest score, analysis of gain score (change from pretest to post test) as well as analysis of cognitive load (mental effort). The significant level for all of the analyses was set at 0.05 .

\section{i. $\quad$ Pretest}

The pretest scoress indicated that PBL group scored higher marks $(\mathrm{M}=5.33 ; \mathrm{SD}=1.84)$ than $\mathrm{EBL}$ group $(\mathrm{M}=4.11$; $\mathrm{SD}=1.91$ ), however the difference was not statictically significant $(t(35)=2.002 ; p>0.05)$. This non-significant result simply implies that both the PBL and EBL groups were comparable and homogeneous in terms of the background knowledge. Table 1 illustrates the outcomes of t-test.

Table 1. Independent Samples Test for pretest scores.

\begin{tabular}{|c|c|c|c|c|c|c|c|c|}
\hline \multicolumn{2}{|c|}{} & \multicolumn{2}{|c|}{$\begin{array}{c}\text { Levene's Test for } \\
\text { Equality of Variances }\end{array}$} & \multicolumn{5}{c|}{ t-test for Equality of Means } \\
\cline { 3 - 9 } & F & Sig. & F & df & Sig.(2-tailed) & $\begin{array}{c}\text { Mean } \\
\text { Difference }\end{array}$ & $\begin{array}{c}\text { Std. Error } \\
\text { Difference }\end{array}$ \\
\hline \multirow{2}{*}{ Pretest } & $\begin{array}{c}\text { Equal } \\
\text { variances } \\
\text { assumed }\end{array}$ & .084 & .774 & 2.002 & 35 & 0.053 & 1.228 & 0.614 \\
\hline & $\begin{array}{c}\text { Equal } \\
\text { variances not } \\
\text { assumed }\end{array}$ & & & 2.004 & 35.000 & 0.053 & 1.228 & 0.613 \\
\hline
\end{tabular}


ii. Learning performance: PBL versus EBL

Table 2 shows the gain scores for both the PBL and EBL groups. The gain score of each participant was determined by computing the difference between the post test score and pretest score. As can be seen, the EBL group $(\mathrm{M}=5.63$; $\mathrm{SD}=3.56)$ outperformed the $\mathrm{PBL}$ group $(\mathrm{M}=3.06 ; \mathrm{SD}=3.53)$ in terms of gain score.

Table 2. Mean and standard deviation for gain score.

\begin{tabular}{|c|c|c|c|c|c|}
\hline & GROUP & $\mathrm{N}$ & Mean & $\begin{array}{c}\text { Std. } \\
\text { Deviation }\end{array}$ & Std. Error Mean \\
\hline \multirow{2}{*}{ Gain score } & PBL & 18 & 3.06 & 3.43 & .81 \\
\cline { 2 - 6 } & EBL & 19 & 5.63 & 3.56 & .82 \\
\hline
\end{tabular}

T-test was carried out to find out whether the participants in EBL settings have performed significantly better than their counterparts. The outcomes of t-test (shown in Table 3) clearly reveal that the learners engaged in EBL scored ${ }_{\text {iii }}$ significantly higher than those who were involved in PBL $(F(35)=-2.24, p=0.031)$.

The possible reason for this expected finding could be that, at the initial learning phase the learners are still struggling to comprehend the unfamiliar concepts and terminology. At this early stage, the learners will try to understand the domain knowledge without yet trying to apply it, and the process is usually dominated by reading and discussion activities [23]. When the learners are engaged in problem solving tasks, they tend to use ineffective problem solving methods (e.g. means-end analysis) due to their scarcity of domain knowledge and problem solving schema. The use of means-ends analysis in problem solving process will involve learners to interact actively and simultaneously with a number of information such as the problem variables, the solution operators, the goals of the problem, and the relation between these information in working memory. At the same time, they must also figure out some feasible ways to solve the problem.Using ineffective problem solving methods may bring about high extraneous cognitive load which in turn will deteriorate learning performance [13].

At the early stage of learning, guidance (e.g., showing worked examples to learners) should be provided to learners. By employing EBL in the early phase, the learners are exposed to the fundamental domain knowledge and problem solving examples. This might help learners acquire a sound basic knowledge and construct problem solving schemas. These knowledge representations and problem solving schemas will be optimally used whenever the learners are faced with problem solving tasks.

In short, it can be concluded that EBL is a more effective method to facililate learning in comparison to PBL.

\section{Mental effort}

The mental efforts invested by participants of PBL and EBL are shown in Table 4. The results indicates that PBL group ( $\mathrm{M}=4.639 ; \mathrm{SD}=0.598)$ invested relatively higher mental effort during the process of learning and answering the test in comparison to EBL group ( $\mathrm{M}=2.395$; $\mathrm{SD}=0.334)$.

$\mathrm{T}$-test was performed to determine whether the difference of mental efforts between PBL and EBL groups was statistically significant. The analysis results indicate that the PBL participants put significantly more mental effort on their learning process than the EBL participants did ( $F(35)$ $=14.199, \mathrm{p}<0.00)$. To put it the other way around, the PBL strategy induced significantly higher cognitive load compared to EBL strategy.

Table 3. Independent Samples Test for gain score between EBL and PBL groups.

\begin{tabular}{|c|c|c|c|c|c|c|c|c|}
\hline \multicolumn{2}{|c|}{} & \multicolumn{2}{|c|}{$\begin{array}{c}\text { Levene's Test for } \\
\text { Equality of Variances }\end{array}$} & \multicolumn{5}{c|}{ t-test for Equality of Means } \\
\cline { 2 - 8 } & $\mathrm{F}$ & Sig. & $\mathrm{F}$ & $\mathrm{df}$ & Sig.(2-tailed) & $\begin{array}{c}\text { Mean } \\
\text { Difference }\end{array}$ & $\begin{array}{c}\text { Std. Error } \\
\text { Difference }\end{array}$ \\
\hline $\begin{array}{c}\text { Gain } \\
\text { Score }\end{array}$ & $\begin{array}{c}\text { Equal } \\
\text { variances } \\
\text { assumed }\end{array}$ & .334 & .567 & -2.241 & 35 & 0.031 & -2.576 & 1.149 \\
\hline $\begin{array}{c}\text { Equal } \\
\text { variances not } \\
\text { assumed }\end{array}$ & & & -2.224 & 34.989 & 0.031 & -2.576 & 1.148 \\
\hline
\end{tabular}

Table 4. Mean and standard deviation for cognitive load (mental effort)

\begin{tabular}{|c|c|c|c|c|c|}
\hline & GROUP & $\mathrm{N}$ & Mean & Std. Deviation & Std. Error Mean \\
\hline \multirow{2}{*}{$\begin{array}{c}\text { Cognitive Load (Mental } \\
\text { effort) }\end{array}$} & PBL & 18 & 4.639 & .598 & .141 \\
\cline { 2 - 6 } & EBL & 19 & 2.395 & .334 & .077 \\
\hline
\end{tabular}


Table 5. Independent samples test for cognitive load between EBL and PBL groups.

\begin{tabular}{|c|c|c|c|c|c|c|c|c|}
\hline \multicolumn{2}{|c|}{} & \multicolumn{2}{|c|}{$\begin{array}{c}\text { Levene's Test for } \\
\text { Equality of Variances }\end{array}$} & \multicolumn{5}{c|}{ t-test for Equality of Means } \\
\cline { 3 - 9 } & $\mathrm{F}$ & Sig. & $\mathrm{F}$ & $\mathrm{df}$ & Sig.(2-tailed) & $\begin{array}{c}\text { Mean } \\
\text { Difference }\end{array}$ & $\begin{array}{c}\text { Std. Error } \\
\text { Difference }\end{array}$ \\
\hline $\begin{array}{c}\text { Cognitive } \\
\text { Load } \\
\text { (Mental } \\
\text { effort) }\end{array}$ & $\begin{array}{c}\text { Equal } \\
\text { variances } \\
\text { assumed }\end{array}$ & 2.849 & .100 & 14.199 & 35 & 0.000 & 2.244 & 1.158 \\
\hline & $\begin{array}{c}\text { Equal } \\
\text { variances not } \\
\text { assumed }\end{array}$ & & 13.994 & 26.386 & 0.000 & 2.244 & 1.160 \\
\hline
\end{tabular}

As far as cognitive load is concerned, it is expected that PBL might induce highest cognitive load compared to EBL strategy. One of the possible explanations for these findings is that PBL begins with students who are required to delve into complex, ill-structured problem that encompasses real life and interdisciplinary contents. With the limited prior knowledge, students attempt to identify the nature of the problem through group discussion. After recognising the goal of the problem, the students have to develop and formulate some feasible strategies to solve the problem and determine the information and methodology they need. In the process of finding problem solutions, the students keep on collecting and processing information which might be related to the problem. Eventually, all students are required to discuss and evaluate their final solution with the assistance of the facilitator [17]. Some of these activities might probably bring about high cognitive load. For example, processing information from multiple sources (e.g, books, journals, internet, video clips) to look for a solution for the given problem might induce high cognitive load because the inexperienced problem solvers might not be certain whether or not the materials they are referring to are relevant to the to-be-solved problem. Processing irrelevant information or analysing and comparing information from multiple sources might increase extraneous cognitive load that hamper learning.

Apart from that, as previously mentioned, novice learners with low prior knowledge commonly lack the experience and effective schema for problem solving. Therefore, novice learners might attempt to solve the problem using weak strategies, such as means-ends strategy, which involves interaction with many pieces of information. Such strategy induces high cognitive load because processing too many interacting elements imposes a high demands on a novice's cognitive system [6].

In sum, this research finding suggests that teaching methods that emphasise on problem solving at the beginning of learning phase might induce high cognitive load, especially for novice learners.

\section{Conclusions}

Within the sphere of present study, the findings reveal that EBL is a more effective way to enhance learning performance compared to PBL. This is because EBL is considered as a guided teaching method that assists learners to construct complete knowledge representation as well as problem solving schemas that can be ultilised when dealing with problem solving tasks. In addition, the current research also discovers that EBL induces lower cognitive load during the process of learning and answering the test. This is mainly because learners engaged in EBL are not involved in problem solving activities which usually cause high cognitive load due to interaction with many pieces of information.

\section{Limitations and Future Research}

The ability to generalise from the current research outcomes is limited due to several reasons. Firstly, current research investigated the impact of EBL and PBL on university students, it is not certain whether similar findings can be replicated on students in different age groups, for instance, high school students or primary school students. Secondly, the current studies put the focus on novice learners, therefore, it is not sure whether the same results can be yielded if EBL is applied on expert learners. Thirdly, it is expected that the current findings might not be able to generalise to the other non-engineering learning domains, such as sociology, psychology, and medical sciences. These limitations have revealed several new avenues of research. Further investigation should replicate the current research on different groups of students. Furthermore, factorial experimental design can be used in order to see its impact on various types of learners (e.g., novice leaners versus expert learners). Additionally, future researcher can embark on the similar research but in different learning domains in order to see whether comparable outcome can be obtained.

\section{Acknowledgements and Declaration}

The present research is financially supported by Research, Innovation, Commercialisation, and Consultation Office (ORRIC) of the University Tun Hussein Onn Malaysia with project grant VOT 0816. The contents of this paper have been presented at the Shanghai International Conference on Social Science, 13-15 Sept 2014. 


\section{REFERENCES}

[1] Habib, F., Eshra, D.K., Weaver, W., \& Newcomer, J. (1999). Problem-based Learning: A new approach for nursing education in Egypt. Journal of Multicultural Nursing \& Health. Vol: 5(3), pp.6-11

[2] Mergendoller, J., Maxwell, N.L., \& Bellisimo, Y. (2006). The Effectiveness of Problem-based Instruction: A comparison Study of Instructional Methods and Student Characteristics. The Interdisciplinary Journal of Problem-based Learning. Vol: 1(2), pp.49-69

[3] McParland, M., Noble, L.M., \& Livingston, G. (2004). The effectiveness of problem-based learning compared to traditional teaching in undergraduate psychiatry. Medical Education. Vol: 38. pp.859-867

[4] Jabbari, H., Bakhshian,F., Alizadeh, M., Alikhah, H., \& Behzad, M.N. (2012). Lecture-based Versus Problem-Based Learning Methods in PublicHealth Course for Medical Student. Res Dev Med Educ, Vol:1(2), pp.31-35

[5] Lai, C.S. (2012). Problem- Based Learning vs Example-Based Learning: From the Perspective of Cognitive Load Theory. Paper presented in the $8^{\text {th }}$ Biennial Conference of the Comparative Education Society of Asia (CESA). 8-1 $11^{\text {th }}$ July 2012. Chulalongkorn University, Bangkok.

[6] Kirschner, P.A., Sweller, J., \& Clark, R.E. (2006). Why Minimal Guidance During Instruction Does Not Work: An analysis of the failure of Constructivist, Discovery, Problem-based, Experiential, and Inquiry-based Teaching. Educational psychologist. Vol: 41(2), pp.75-86.

[7] Lai, C.S. (2009). Computer-Assisted example-based learning. The effects of self-explanation and instructional explanation on transfer performance. Paper presented at the International conference on Information Communication Technology in Education. Corfu, Greece ( 9 - 11th July 2009)

[8] Van Gog, T., Paas, F., \& van Merriënboer, J.J.G. (2008). Effects of studying sequences of process-oriented and product-oriented worked-examples on troubleshooting transfer efficiency. Learning and Instruction. Vol: 18(3), pp.211-222

[9] Lai, C.S. (2010). Learning with Worked-Out Problems: The Impacts of Instructional Explanation and Self-Explanation Prompts on Transfer Performance. Journal of Technical Education and Training. Vol: 2(2). Pp: 1-15

[10] Van Gog, T., Paas, F., \& van Merriënboer, J.J.G. (2006). Effects of process-oriented worked-examples on troubleshooting transfer performance. Learning and Instruction. Vol: 16(2), pp.154-164.
[11] Schworm, S., \& Renkl, A. (2006). Computer-supported example-based learning: When instructional explanation reduce self-explanations. Computers \& Education. Vol: 46(4), pp.426-445

[12] Große, C.S., \& Renkl, A. (2006). Effect of multiple solution methods in mathematics learning. Learning and Instruction. Vol: 16 (2), pp.122-138.

[13] Renkl, A., Stark, R., Gruber, H., \& Mandl, H. (1998). Learning from worked-out examples: The effects of example variability and elicited self-explanations. Contemporary Educational Psychology. Vol: 23, pp.90-108

[14] Große, C.S., \& Renkl, A. (2007). Finding and Fixing Errors in Worked Examples: Can this foster learning outcomes?. Learning and Instruction. Vol: 17, pp.612-634.

[15] Houghton, R. S. (2004). Rationale for Multimedia Use and Instruction in Education, v7.81. Western Carolina University. Retrieved $22^{\text {nd }}$ Feb 200, from http://www.wcu.edu/ceap/HO UGHTON/MM/rationale/rationaleMM.html

[16] Barrows, H.S., \& Tamblyn, R.M. (1980) Problem-Based Learning: An Approach to Medical Education. New York: Springer Publishing Company.

[17] Ertmer, P.A., \& Simons, K.D. (2006). Jumping the PBL Implementation Hurdle: Supporting the Efforts of K-12 Teachers. The Interdisciplinary Journal of Problem-based Learning. Vol: 1(1), pp.40-54

[18] Hong, J.C., Chu, S.T., \& Liu, T.C. (2005, June). Strategies For Construction Problem-Based Learning Curruculum. Paper presented at the International Conference on Problem-Based Learning, Lahti, Finland. Retrieved 19th May 2007, from http://www.lpt.fi/pblconference/full_papers/13 f ull papers.htm

[19] Sweller, J., van Merriënboer, J.J.G., \& Paas, F. (1998). Cognitive Architecture And Instruction Design.

[20] Sweller, J. (1988). Cognitive Load During Problem Solving: Effects on Learning. Cognitive Science. Vol: 12, pp.257-285

[21] Paas, F., \& van Merriënboer, J.J.G. (1994). Variability of worked examples and transfer of geometrical problem solving skills: A cognitive-load approach. Journal of Educational Psychology. Vol: 86, pp.122-133

[22] Hart, S.G., \& Staveland, L.E. (1988). Development of NASA-TLX (Task Load Index): Results of experimental and theoretical research. In P.A. Hancock, \& N. Meshkati (Eds), Human Mental Workload. (pp.139-183). Amsterdam: North Holland

[23] VanLehn, K. (1996). Cognitive skill acquisition. Annual Review of Psychology. Vol: 47, pp.513-539. 